\title{
A Tribute to Dr. David Lanier
}

David Meyers, $M D$

Most individual primary care Practice-based Research Networks (PBRNs) share a common life course. They usually begin as a twinkle in someone's eye, are born, develop through an infancy to take first steps in conducting research, grow, and hopefully survive a tumultuous adolescence when first papers are published and competitive grants are received, and then enter a mature period of productivity. They may experience neglect or become ill, and, with care, return to health. Some older networks, such as PROS, remain vibrant, whereas others enter a period of senescence and some such, as the grandparent of US PBRNs, ASPN, passes away.

If the US primary care PBRN movement is viewed within a similar framework, in 2011 it may be emerging into a productive young adulthood. Certainly productivity is high, with three PBRNs being awarded over $\$ 7.5$ million in 2010 to perform comparative effectiveness research in primary care settings and many others being incorporated into NIH CTSA cores. This growing maturity and success is the result of the efforts of many dedicated people who share a belief in the wisdom of practicing clinicians, the need to actively engage them in all aspects of knowledge generation, and a commitment to supporting them as they work to improve the health of their patients and communities.

The Agency for Healthcare Research and Quality (AHRQ) is proud to have played a part in the growth of the PBRN movement and is particularly proud of the specific contributions of Dr. David Lanier. Over the past decade, Dr. Lanier has provided visionary leadership as he designed, imple-

This article was externally peer reviewed.

Submitted 25 April 2011; revised 25 April 2011; accepted 2 May 2011.

From the Center for Primary Care, Agency for Healthcare Research and Quality, Rockville, Maryland.

Funding: none.

Conflict of interest: none.

Corresponding author: David Meyers, MD, 540 Gaither Road, Rockville, MD 20850 (E-mail: David.Meyers@ahrq.hhs.gov). mented, and nurtured AHRQ's primary care PBRN Initiative.

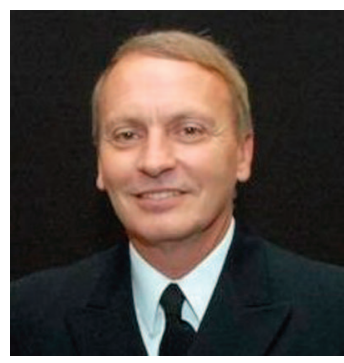

Dr. David Lanier.

In 1999, Dr. Lanier brought to AHRQ's senior management a plan for implementing a somewhat vague sentence in the agency's reauthorizing language that directed the newly renamed AHRQ to employ research strategies and mechanisms that link research directly with clinical practice in geographically diverse locations throughout the country, including the use of "provider-based research networks especially (in) primary care.” At that time, there was a handful of active PBRNs in the United States, and few had received any federal research funding. The agency embraced his vision.

Reflecting his intuition that the time was right for AHRQ to invest in PBRNs, almost 100 applications were received for the agency's initial funding solicitation. Between 2000 and 2004, David conceived, wrote, oversaw, and served as the project officer for a series of four competitive research grant programs for primary care PBRNs. He responded to calls from the community for assistance and shared learning opportunities by establishing AHRQ's national PBRN resource center and overseeing the development of a PBRN resource website. In addition, in 2005, he established a national research conference dedicated to PBRN methodologies and findings that attracts between 200 and 300 researchers each year. 
By 2005, the number of active primary care PBRNs in the United States had grown to more than 100. Dr. Lanier, recognizing the growing maturity of the field, led AHRQ to develop a rapidcycle research contract mechanism. In 2007, AHRQ awarded master contracts to 10 groups, representing 16 mature PBRNs. To date, AHRQ has invested more than $\$ 10$ million in more than 40 contracts. David was the project officer for all them and a task order officer for many. These investments resulted in policy-relevant evidence on the costs of data collection and reporting for quality measurement in primary care offices, created a national benchmark data set for the AHRQ Safety of Practice outpatient survey instrument, and contributed to the design of the National Children's Health Study, among many other contributions.

Dr. Lanier patiently and persistently cultivated the interest of AHRQ's federal research partners at $\mathrm{NIH}$, sharing with them the potential of "putting research into practice and practice into research." This has resulted in joint research grant programs between NCI and AHRQ, NIACM-sponsored funding announcements that restrict applications to AHRQ-identified PBRNs, and most notably the centrality of research networks in the trans-NIH Clinical and Translational Science Award initiative. Additionally, his efforts led to a partnership with the Robert Wood Johnson Foundation and the \$9 million Prescription for Health project, which utilized PBRNs to create novel ways of assisting Americans in changing unhealthy behaviors.

Many AHRQ staff, including John Eisenberg, Helen Burstin, Carolyn Clancy, Natalie Alter, Joe
Clift, and myself, as well as many program, grant, and contract staff, contributed to the success of AHRQ's PBRN effort; we did so in response to David Lanier's vision and leadership. On reflection, it is clear that while many contributed some effort, the bulk of the work, from drafting FOAs, to talking with potential applicants, to signing off on invoices, to picking the entrée for lunch, to training new task order officers, to publishing articles, was done by David Lanier.

In their 2006 retrospective, A Short History of Primary Care Practice-based Research Networks: From Concept to Essential Research Laboratories, US PBRN leaders Larry Green and John Hickner wrote, "AHRQ stepped up in the 1990s and led the nation to fund and build capacity for practice-based research by creating specific PBRN programming. It would be difficult to overstate the importance of AHRQ in the maturation of practice-based research in the United States." Today we can say it would be difficult to overstate the importance of Dr. Lanier in the maturation of practice-based research in the United States.

After serving as midwife, kindergarten teacher, coach, and fairy godmother to PBRNs across the country and to the PBRN movement as a whole, in December 2010, David retired from the US Public Health Service Commissioned Corps and AHRQ. He reports that not only is he fully enjoying life in the Southwest but that he is far busier than he thought he would be. In addition to writing poetry, he has become active within organized medicine, is serving on the board of a local arts organization, and is indulging in international travel. 